\title{
ACUTE EPIGLOTTITIS IN CHILDREN: MANAGEMENT OF 27 CONSECUTIVE CASES WITH NASOTRACHEAL INTUBATION, WITH SPECIAL EMPHASIS ON ANAESTHETIC CONSIDERATIONS
}

\author{
Victor F. Blanc, "Michel L. Weber,† Claude Leduc, "Réjean laberge, \\ Roger Desjardins, $\uparrow$ and Gilles Perreault
}

ACUTE EPIGLOTTITIS is a severe, rapidly progressive form of "croup," which most often occurs in children between the ages of one and seven years. Infants as young as two months old, ${ }^{1}$ and adults as old as $66^{2}$ may also be affected. Boys are affected twice as often as girls. This is a true medical emergency, because sudden, unexpected and complete upper airway obstruction is frequent, with a high mortality, reaching 90 per cent in one older series. ${ }^{3}$

This infection is sometimes called "supraglottitis," since it involves predominantly the supraglottic structures of the larynx, mainly the epiglottis and the aryepiglottic folds. The aetiologic agent is almost exclusively the haemophilus infuenzae type B. ${ }^{4}$

Classical symptoms include sudden onset of high fever, toxicity, tachycardia, intense dysphagia, noisy respiration, and pallor. In contrast with laryngitis, a barking cough is usually absent, stridor is less striking, and the voice is usually normal, although somewhat muffled.

Signs of upper airway obstruction such as flaring of the alae nasi and suprasternal, supraclavicular and sternal retractions may be severe, moderate, or even absent initially, and it is essential to recognize that even patients with little or no respiratory distress are at risk of sudden death or irreversible brain damage. Many children assume the typical, easy-to-recognize attitude and position: they are anxious, insist on remaining in the sitting position, and lean forward with the mouth open and tongue somewhat protruding. Drooling saliva is often present, due to the intense dysphagia, and constitutes one of the most important clues to the diagnosis.

Once the diagnosis is suspected, care must be taken to keep the patient sitting and breathing oxygen and one must not attempt to examine the pharynx with a tongue depressor; this manoeuvre may precipitate complete obstruction, or perhaps trigger a vagal reflex with cardiac arrest.

In older patients the swollen epiglottis can sometimes be well visualized without danger simply by having the patient open his mouth.

If the clinical condition permits, the diagnosis can be readily confirmed by radiological studies of the soft tissues of the neck. ${ }^{5-8}$ The lateral film demonstrates easily the considerable swelling of the epiglottis and aryepiglottic folds (Figure 1), as compared to their normal appearance (Figure 2).

From the Departments of Anaesthesiology ${ }^{*}$, Paediatricst, Otolaryngologył and Radiologyt, Hôpital Sainte-Justine pour les Enfants and Université de Montréal.

Mailing address (V.F.B.): Department of Anaesthesiology, Hôpital Sainte-Justine, 3175 Chemin de la Côte Ste-Catherine, Montréal, Québec, Canada, H3T 1C5. 


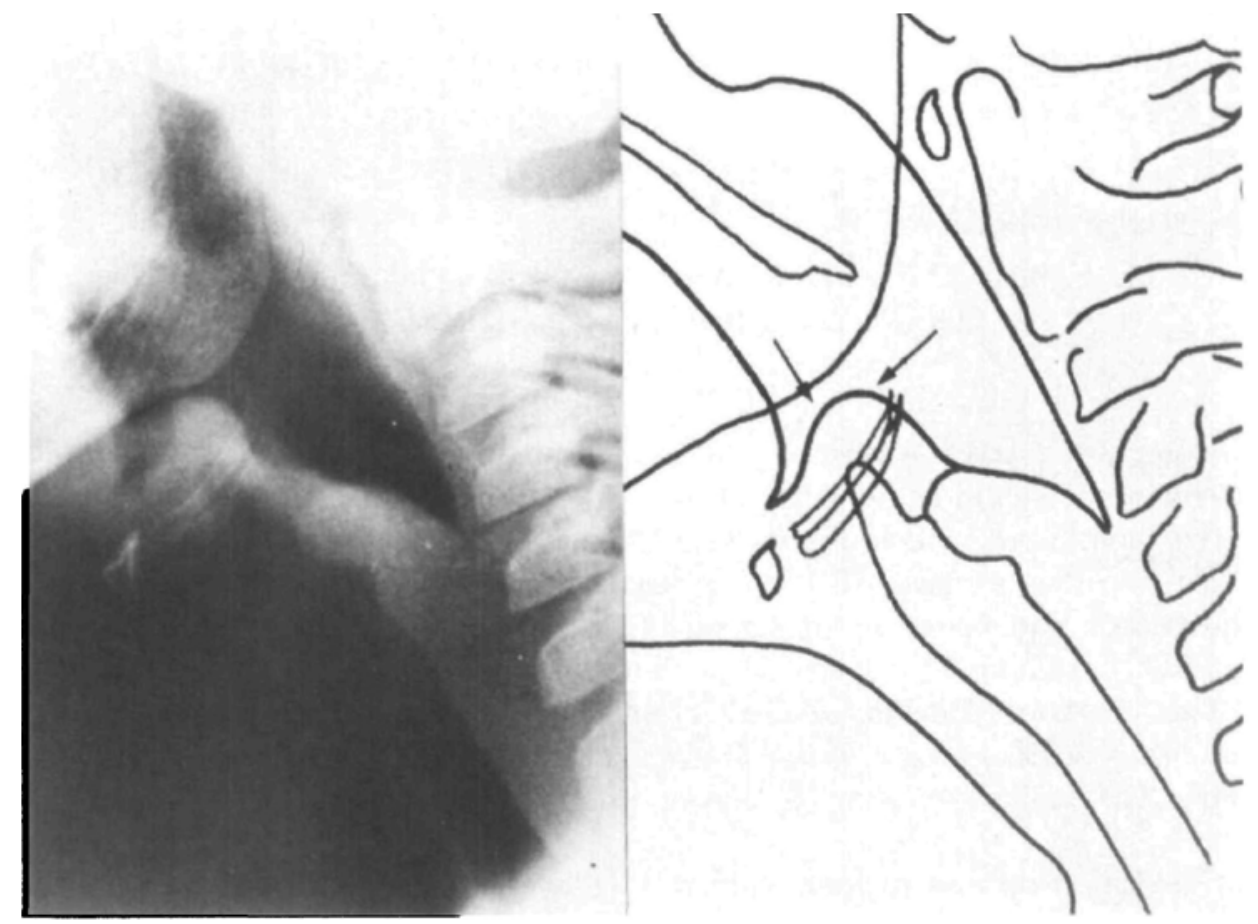

Ficure 1. Lateral radiography of the neck and counter tracing showing swelling of the epiglottis (arrows) and thickening of the aryepiglottic folds: epiglottitis.

Polymorphonuclear leucocytosis, rarely seen with laryngitis, is often striking. Cultures of blood and epiglottis are often positive, depending on several technical factors; in one recent report, ${ }^{4}$ blood and epiglottic cultures were both positive for haemophilus influenzae in 26 of 32 patients.

Direct laryngoscopy is always pathognomonic, demonstrating a large, almost spherical, oedematous, cherry-red epiglottis, with inflammation in the areas surrounding it, in the aryepiglottic folds, sometimes extending to the vocal cords and the subglottic region.

Because of the impending disaster inherent in this situation, even when patients are watched very closely in the best conditions, most North American authors have recommended that preventive tracheostomy be performed as soon as the diagnosis is made. ${ }^{0-13}$

Immediate preventive nasotracheal intubation instead of tracheostomy has been advocated by Australian, ${ }^{14,15}$ European ${ }^{16-20}$ and, more recently, North American authors. ${ }^{21-30}$ It is important to note that before tracheostomy or intubation can be performed, patients with acute epiglottitis can be effectively helped by gentle assisted ventilation with a bag and mask without deleterious effect on the airway obstruction.

The present report describes our experience with 27 successive patients treated by nasotracheal intubation and represents particularly the anaesthetic point of view, which has received little attention in the literature. 


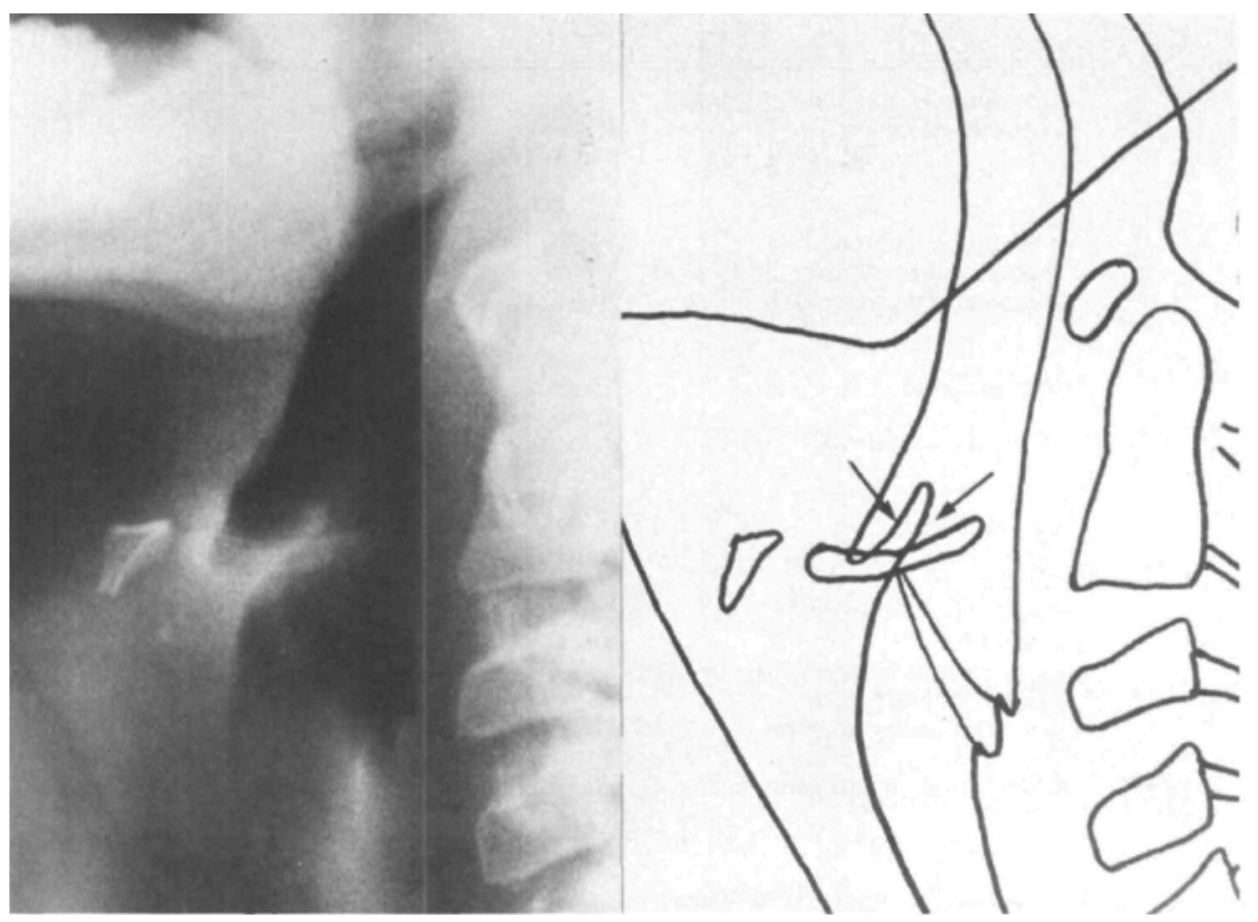

Figune 2. Lateral radiography of the neck and counter tracing showing normal epiglottis (arrows).

\section{Clinical Experience}

From January 1, 1974 to January 31, 1976 ( 25 months ), 29 patients were admitted to l'Hôpital Sainte-Justine pour les Enfants with acute epiglottitis. The first 14 cases have already been reported elsewhere ${ }^{29}$ Several patients who were dead on arrival were not included in this series. Two of the 29 patients were excluded: the first had a tracheostomy performed in another hospital, and the second arrived at the emergency room of our hospital with a tracheal tube in place, but in deep coma, with irreversible brain damage. The remaining 27 patients were all treated following the protocol described in this report. Pertinent clinical data on these patients are summarized in Table I. All patients were managed according to the following protocol:

\section{Protocol}

(1) If a patient clinically suspected of having acute epiglottitis is admitted to the emergency room, immediate examination of the pharynx is prohibited. The patient is kept in a sitting position, breathing humidified oxygen. A venous line is placed as soon as possible.

(2) Consultants in anaesthesiology and otolaryngology are called at once.

(3) If the clinical condition permits, radiological studies of the soft tissues of the neck are quickly obtained in the emergency room. The patient remains in a 
TABLE I

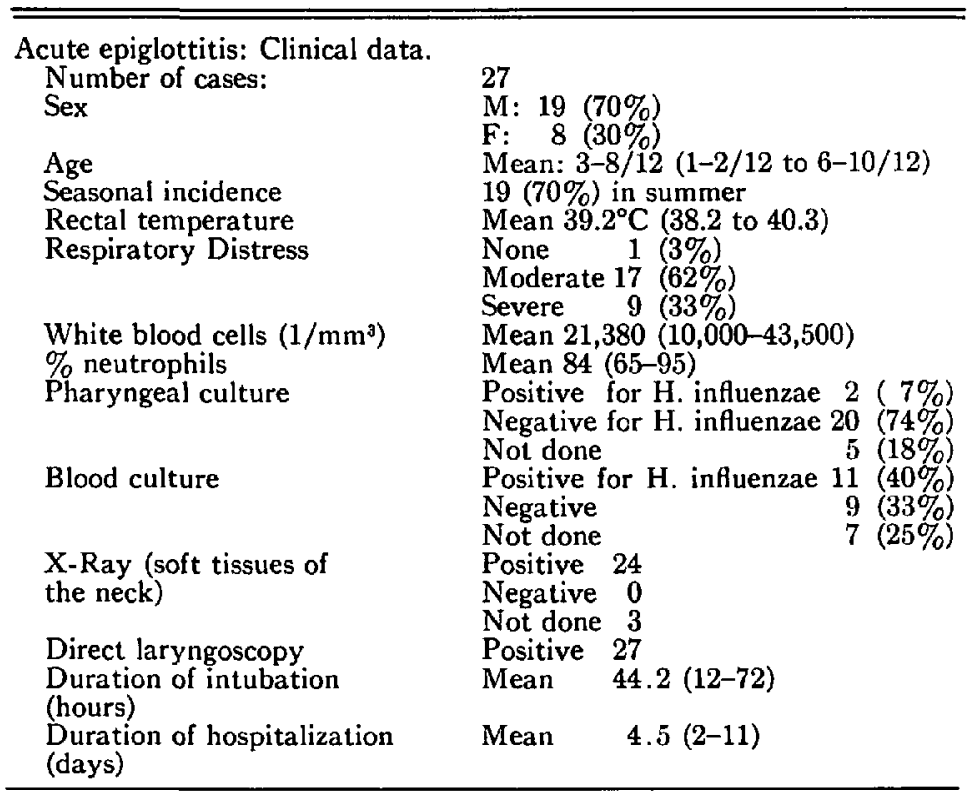

sitting position during this very short procedure and an experienced physician remains in constant attendance with the necessary facilities for mask and oxygen positive-pressure ventilatory support.

(4) If the X-ray study is diagnostic, the patient is immediately transferred to the operating room for direct laryngoscopy under general anaesthesia. At this time throat and blood cultures are obtained. If the X-ray study shows signs of laryngitis instead of epiglottitis, therapy for laryngitis is instituted.

(5) If direct examination of the larynx confirms the diagnosis of epiglottitis, an uncuffed polyvinylchloride nasotracheal tube is inserted by an anaesthesiologist. The calibre of the tube is one or two sizes smaller than normal for the patient's age.

(6) The patient is kept one hour in the recovery room, breathing humidified air and oxygen $\left(\mathrm{F}_{\mathrm{O}_{2}}=0.3\right)$ delivered through a plastic T-tube and is then transferred to the intensive care unit for continuous observation.

(7) Tracheobronchial toilet consists of hourly changes of position, chest vibration or percussion, instillation of small volumes $(0.25 \mathrm{to} \mathrm{l} \mathrm{ml})$ of normal saline into the trachea, careful aspiration of secretions and manual hyperinflation of the lungs, in that order.

(8) The following medications are given: ampicillin (200 $\mathrm{mg} / \mathrm{kg} / 24$ hours, intravenously, in four divided doses); acetylsalicylic acid (rectally, as necessary); fluids, electrolytes and glucose (intravenously); diazepam $(0.2 \mathrm{mg} / \mathrm{kg} / \mathrm{dose}$, intravenously, as necessary, for sedation).

(9) If general manifestations of acute infection have disappeared (24 to 36 hours) and if the swelling of the epiglottis has regressed, extubation is attempted early in the morning in the operating room, under the supervision of both an anaesthetist and an otolaryngologist. The size of the epiglottis is examined every 
TABLE II

Anaesthetic Techniques for Direct Laryngoscopy and Nasotracheal Intubation in ACUTE EPIGLOTTITIS

\begin{tabular}{|c|c|c|c|}
\hline Techniques & Agents and doses & No. of cases & Total no. \\
\hline Intravenous & $\begin{array}{l}\text { Thiopentone }(5 \mathrm{mg} / \mathrm{kg})+\text { succinylcholine }(1 \mathrm{mg} / \mathrm{kg}) \\
\text { Diazepam }(0.4 \mathrm{mg} / \mathrm{kg}) \text { + succinylcholine }(1 \mathrm{mg} / \mathrm{kg}) \\
\text { Diazepam }(0.2 \mathrm{mg} / \mathrm{kg}) \text { + Ketamine }(2 \mathrm{mg} / \mathrm{kg}) \\
\text { Ketamine }(2 \mathrm{mg} / \mathrm{kg})+\text { Xylocaine spray }(3 \mathrm{mg} / \mathrm{kg})\end{array}$ & $\begin{array}{l}4 \\
4 \\
1 \\
1\end{array}$ & 10 \\
\hline Inhalational & $\begin{array}{l}\text { Halothane }(1.5-2 \%)+\text { Oxygen } \\
\text { Halothane }(1-2 \%)+\mathrm{N}_{2} \mathrm{O}+\text { Oxygen }(50 \%)\end{array}$ & $\begin{array}{r}10 \\
1\end{array}$ & 11 \\
\hline Mixed & $\begin{array}{l}\text { Diazepam }(0.2 \mathrm{mg} / \mathrm{kg})+\text { Halothane }(1-1.5 \%)+\text { Oxygen } \\
\text { Ketamine }(1-2 \mathrm{mg} / \mathrm{kg})+\text { Halothane }(1-2 \%)+\text { Oxygen }\end{array}$ & $\begin{array}{l}1 \\
3\end{array}$ & 4 \\
\hline \multicolumn{2}{|l|}{ No anaesthesia } & 2 & 2 \\
\hline \multicolumn{2}{|c|}{ Total number of cases } & 27 & 27 \\
\hline
\end{tabular}

12 hours with a tongue depressor. When doubt exists about the size of the epiglottis, laryngoscopy is performed under general anaesthesia before extubation is carried on.

(10) The patient is observed in a mist tent for an additional 24 hours and then is discharged with orally administered ampicillin or amoxicillin for a total of ten days.

This protocol does not indicate what anaesthetic technique is to be used; therefore, each anaesthetist was free to choose the one he considered preferable for each particular case. The review of the anaesthetic records is summarized in Table II.

Premedication with intravenous atropine $(0.005-0.01 \mathrm{mg} / \mathrm{kg})$ was given to 11 patients ( 40.7 per cent), particularly to those receiving intravenous or mixed (intravenous + inhalational) anaesthesia. It was considered unnecessary in the remaining patients, who were usually those anaesthetized by inhalational techniques.

In summary, inhalational techniques were preferred for the younger patients (one to three years old) and intravenous techniques or intravenous inductions were chosen for the older or less cooperative children (three to six years old). The severity of the respiratory distress was a less important factor in the choice of anaesthetic technique. Mask ventilation was always possible and efficient, and no important difficulty in direct laryngoscopy or in nasotracheal intubation was encountered.

Monitoring of the electrocardiogram by cardioscope with beep and alarm, of the body temperature by rectal thermocouple and of the heart sounds by precordial stethoscope was obligatory for every case. Fluid balance during anaesthesia was maintained with 5 per cent dextrose in 0.2 per cent sodium chloride (2-4 $\mathrm{ml} / \mathrm{kg}$ per hour).

The total time for anaesthesia, laryngoscopy, blood and throat cultures, nasotracheal intubation, and safe arrival in the recovery room, ranged between 15 and 65 minutes (mean, 37.8 minutes).

One of our patietns (four years nine months old) was intubated in the emergency room without anaesthesia, because he presented with a cardio-respiratory arrest from which he recuperated with no neurological sequelae.

Nasotracheal tubes were surprisingly well tolerated: 16 patients received no 
sedation at all, and 11 received an occasional dose of diazepam $0.2 \mathrm{mg} / \mathrm{kg}$ administered intravenously.

Very few complications were encountered: four patients extubated themselves spontaneously after 1 to 64 hours of intubation. Three of these patients were reintubated 1, 3 and 16 hours, respectively, after the time of the initial intubation. It is important to note that all these reintubated patients had received Ketamine as the anaesthetic agent and no sedation while in the intensive care unit. One of our patients presented a mild laryngitis after extubation, which was easily managed with nebulized racemic epinephrine delivered by IPPB.

One patient had a transient segmental atelectasis and two other patients presented pulmonary lobar infiltrations associated with the disease.

All patients left the hospital without manifest sequelae after an average of 4.5 days of hospitalization (range 2 to 11 days). The longer hospitalization periods (more than six days) were observed in patients with associated problems such as cardio-respiratory arrest, pneumonia, ketogenic hypoglycaemia, or febrile seizures.

Nasotracheal intubation was maintained for an average duration of 44.2 hours (range 12 to 72 hours). To date, we have encountered no noticeable sequelae during follow-up examinations.

\section{Discussion}

As in other series, we have found in our patients a net predominance of the disease in males.

While most textbooks of paediatrics consider epiglottitis to be a disease affecting children aged three to seven years, in the present series we note that half the children are less than three years old. This is an important finding, because we believe one must be aware of the possibility of this disease occurring even in very young children, in whom the clinical diagnosis is more difficult. The distinct summer incidence found in our series is not noted in others. We do not have a valid explanation for this fact, unless it is related in one way or another to the weather conditions particular to Montreal.

It is clear that one of the principle factors of success in the treatment of epiglottitis is the maintenance of knowledge of the disease and a very high index of suspicion for it among the doctors who work in emergency rooms, so that an early diagnosis may be made. A harmonious multi-disciplinarian collaboration among paediatricians, anaesthesiologists, otolaryngologists, and radiologists, who are all guided by the same protocol, is just as important.

The ideal treatment for the disease is now well known. The judicious use of appropriate antibiotics is accepted by everyone. Ampicillin is certainly the antibiotic of first choice. In case of severe penicillin allergy, lack of rapid response to therapy, or for those regions in which haemophilus resistant to ampicillin has frequently been identified, chloramphenicol is probably the best first choice.

The use of racemic epinephrine given by IPPB has seemed to be efficaceous in sporadic cases ${ }^{31}$ and useless in others. ${ }^{28}$ Since the evolution of the disease under the influence of antibiotics alone is favourable in about half the cases, it is impossible to judge the efficacy of this treatment based on some anecdotal cases. Because 


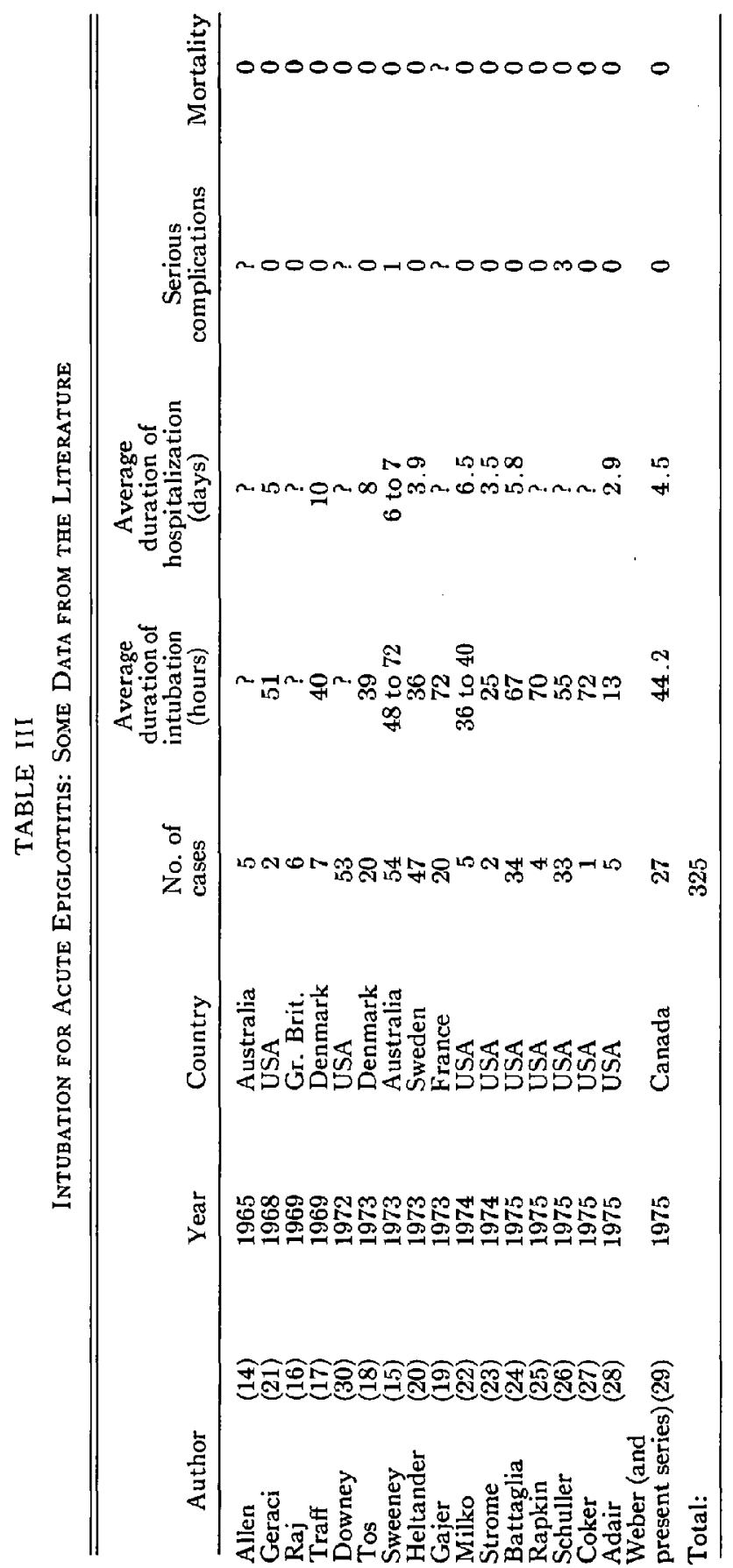


of the rarity and gravity of the illness, a double blind study is difficult to conduct, and would be, moreover, subject to attack from a moral point of view. This form of treatment could then seem to be indefensible. The same considerations are probably applicable to the use of corticosteroids which have been advocated by some. ${ }^{23}$

Acknowledging the disasters, publicized and unpublicized, engendered by conservative treatment alone, it is now clear that this approach, which could moreover give rise to severe legal complications, must be totally abandoned. We believe that the problem of acute epiglottitis without impressive dyspnoea, in which one might be tempted to employ a conservative treatment, constitutes one of the most formidable pitfalls in paediatrics. The authors of the present report consider that the only valid treatment consists of protecting the upper airway by nasotracheal intubation, performed immediately after the diagnosis is made, while waiting for the antibiotics to take effect and promote an important diminution of the volume of the epiglottis. More than 300 cases treated in this manner have been reported in the world literature (Table III). The same studies tend to indicate that nasotracheal intubation is clearly superior to tracheostomy. ${ }^{20,26}$ If one considers the studies as a whole, nasotracheal intubation offers the following advantages over tracheostomy:

(1) Lowest mortality, practically nil.

(2) Smallest incidence of immediate or late complications. In certain studies ${ }^{20}$ a follow-up endoscopy was even done to prove this point.

(3) Absence of scarring.

(4) Elimination of the problems sometimes associated with removal of tracheostomy tubes in very young infants.

(5) Often a shorter hospitalization.

Moreover, it appears to us that in a regional hospital there are more chances of having the benefit of a 24-hour service by competent anaesthetists, capable of performing an intubation (which must in any case be done for a tracheostomy performed under good conditions), than that of a surgeon who regularly does tracheostomies on young children.

Let us mention, finally, that in upper respiratory obstructions in children, the mortality associated with accidental extubation would be much less with intubation than with tracheostomy, because the tracheal tube has a dilating effect on the oedematous tissues, as opposed to the effect of tracheotomy, thus allowing a period of 30 to 60 minutes free of obstruction after accidental extubation. This facilitates an easy reintubation. ${ }^{26}$

As a matter of fact, we have never had an extremely difficult or impossible nasotracheal intubation for acute epiglottitis, using several very different techniques of general anaesthesia. Nevertheless, in our hospital, the anaesthesiologist always works in intimate collaboration with an otolaryngologist who is ready for emergency bronchoscopy and/or tracheostomy in these patients.

The fact that we never had too much difficulty in ventilating our patients with a mask is most important.

Inhalational anaesthesia (halothane) as described by some Australian and European authors ${ }^{15-18}$ is the most convenient and safe technique. Halothane, oxygen and a depolarizing relaxant is another proposed choice. ${ }^{20}$ 
Intravenous anaesthesia (thiopentone, diazepam) and succinylcholine after an oxygenation period of three to five minutes, is a rapid technique of anaesthesia ${ }^{21,22}$ which can be associated with the Sellick manoeuvre. ${ }^{32}$ However, we must stress a warning; less experienced anaesthetists or those not experienced in paediatric anaesthesia should avoid the use of intravenous induction and relaxants in this disease.

Ketamine presents no clear advantages over the commonly used drugs. On the contrary, ketamine seems to increase the incidence of accidental extubation in these patients, especially when associated with inadequate sedation. Indeed, we are deeply impressed by the fact that three of five patients who received ketamine and no sedation had an accidental extubation. The use of this agent with its potential for vomiting, salivation, bad dreams, excitement, restlessness and hallucinations ${ }^{33}$ is somewhat controversial for laryngoscopy and nasotracheal intubation in acute epiglottitis. If one particular reason is to be found to justify using ketamine in these patients, then a convenient regular sedation is mandatory for as long a time as the patient requires to emerge from the ketamine dissociation.

Nevertheless, Schuller \& Birck ${ }^{26}$ found an identical incidence of accidental extubation ( 11 per cent) in a series of 33 children anaesthetized with more conventional methods.

The ideal time for extubation remains difficult to definite. The criteria we have adopted are: disappearance of general manifestations of acute toxic infection and regression of epiglottic swelling ( 12 to 72 hours). Nevertheless, Adair and Ring ${ }^{28}$ report an average time of intubation of only 13 hours without complications (Table III).

\section{SUMMARY}

Twenty-seven consecutive cases of acute epiglottitis in children were treated by nasotracheal intubation during a 25 -month period.

The duration of intubation averaged 44.2 hours. No mortality or morbidity occurred. Mean hospitalization was 4.5 days.

Anaesthetic techniques are discussed. Ketamine is a somewhat controversial choice for these patients as it can enhance excitement, restlessness, and accidental extubation.

This study reconfirms the ease of maintaining an assured airway by nasotracheal intubation in cases of acute epiglottitis.

\section{RÉSUMÉ}

L'Hôpital Sainte-Justine pour les Enfants (Montréal) a admis 27 enfants atteints d'épiglottite aiguë d'origine infectieuse, du ler janvier 1974 au 31 janvier 1976 ( 25 mois). Tous ces enfants ont été traités à l'aide de lintubation nasotrachéale, d'après un protocole élaboré conjointement par les départements de pédiatrie, d'anesthésiologie, d'oto-rhino-laryngologie et de radiologie.

La durée moyenne de l'intubation a été de $\mathbf{4 4 . 2}$ heures. La mortalité et la morbidité reliées à ce traitement ont été nulles. La durée moyenne de l'hospitalisation a été de 4.5 jours.

Différentes techniques d'anesthésie générale ont été employées et discutées. Le 
choix de la ketamine, pour ces malades, nous semble pour le moins très discutable dans la mesure où le réveil de la dissociation à la ketamine peut être agité et, sans sédation convenable, peut augmenter l'incidence d'extubations accidentelles (trois de nos cinq patients ayant reçu de la ketamine ont dû être réintubés).

Cette étude confirme une fois de plus que l'intubation nasotrachéale est une méthode excellente pour le traitement des épiglottites aiguës.

Acknowledgment: Paediatricians, otolaryngologists, radiologists, microbiologists as well as the anaesthesiologists and many nurses of the recovery room and of the intensive care unit, as well as many residents, contributed to the excellent care of these patients. The authors are especially proud of the team spirit which rendered this study feasible.

\section{REFERENCES}

1. GaUtai, H.P. Acute epiglottitis. Br. Med. J. 3: 647 (1970).

2. Castelman, B.C. \& McNeely, B.U. Case records of the Massachusetts General Hospital. Case 17-1967. N. Engl. J. Med. 276: 920 (1967).

3. Jones, H.M. \& CAMPs, F.E. Acute epiglottitis: supraglottitis. Practitioner 178: 223 ( 1957 ).

4. Margolis, C.Z., Colletti, R.B., \& Grundy, G. Hemophilus influenza type b: the etiologic agent in epiglottitis. J. Pediatr. 87: 322 (1975).

5. Dunbar, J.S. Epiglottitis and croup. J. Canad. Assoc. Radiol. 12: 86 ( 1961 ).

6. Poole, C.A. \& Altaran, D.H. Acute epiglottitis in children, Radiology 80: 798 (1963).

7. Dunbar, J.S. Upper respiratory tract obstruction in infants and children. Am. J. Roentgenol. Radium Ther. Nucl. Med, 109: 227 (1970).

8. RAPKIN, R.H. The diagnosis of epiglottitis, the simplicity and reliability of radiographs of the neck in the differential diagnosis of the croup syndrome. J. Pediatr. 80: 96 (1972).

9. RApkis, R.H. Acute epiglottitis: pitfalls in diagnosis and management. Clin. Pediatr. 10: $312(1971)$.

10. Margolis, C.Z., Ingrair, D.L., \& Meyen, J.H. Routine tracheotomy in hemophilus influenzae type b epiglottitis. J. Pediatr. 81: 1150 (1972).

11. Rapkin, R.H. Tracheostomy in epiglottitis. Pediatrics. 52: 426 (1973).

12. Johnson, G., Sullivan, J.L., \& Bishop, L.A. Acute epiglottitis: review of 55 cases and suggested protocol. Arch. Otolaryngol, 100: 333 (1973).

13. BAss, J.W. Routine tracheotomy for epiglottitis: what are the odds? J. Pediatr. 83: 510 (1973).

14. Allen, T.H. \& Steven, I.M. Prolonged intubation in infants and children. Brit. J. Anaesth. 37: 566 (1965).

15. Sweeney, D.B., Allen, T.H., \& Steven, I.M. Acute epiglottitis: management by intubation. Anesth. Intens. Care 1: 526 ( 1973).

16. RaJ, P.P., Larand, D.G., \& DiBa, Y.T. Acute epiglottitis in children: a respiratory emergency. Brit. J. Anaesth. 41: 619 (1969).

17. TrafF, B. \& Tos, M. Nasotracheal intubation in acute epiglottitis. Acta Otolaryngol. 68 : $363(1969)$.

18. Tos, M. Nasotracheal intubation in acute epiglottitis. Arch. Otolaryngol. 97: 373 (1973).

19. Gajer, M. \& Huault, G. Les épiglottites aiguës. Journees Parisiennes de Pediatrie, Flammarion (Paris) , 47 (1973).

20. Heltander, P. \& Lee, P. Treatment of acute epiglottitis in children by long-term intubation. Acta Otolaryngol. 75: 379 (1973).

21. Geraci, R.P. Acute epiglottitis: management with prolonged nasotracheal intubation. Pediatrics 41: 143 (1968)

22. Milko, D.A., Mahshak, G., \& Striker, T.W. Nasotracheal intubation in the treatment of acute epiglottitis. Pediatrics 53: 674 (1974).

23. Stroxe, M. \& JAFFe, B. Epiglottitis indivualized management with steroids. Laryngoscope 84: 921 (1974).

24. Battaglia, J.D. Management of acute epiglottitis by nasotracheal intubation. Am. J. Dis. Child. 129: 334 (1975).

25. Rapkin, R.H. Nasotracheal intubation in epiglottitis. Pediatrics 56:110 (1975). 
26. SChuller, D.E. \& BirCK, H.G. The safety of intubation in croup and epiglottitis: an eightyear follow-up. Laryngoscope 85: 33 (1975).

27. Coker, S.B. \& SCherz, R.G. Safe alternative to tracheostomy in acute epiglottitis. Am. J. Dis. Child. 129: 136 (1975).

28. Adam, J.C. \& RING, W.H. Management of epiglottitis in children. Anesth. Analg. 54: 622 (1975).

29. Weber, M.L., Des jardins, R., Perreault, G., Rivard, G., \& Turnel, Y. Acute epiglottitis in children - Treatment with nasotracheal intubation: report of 14 consecutive cases. Pediatrics 57: 152 (1976).

3C. Downey, M.J., Kane, L.A., \& Selord, L.C. Nasotracheal intubation in infants and children. N.Y. State J. Med. 72: 2521 (1972).

31. McNally, G.F. \& Lohman, P.H. Acute epiglottitis managed with nebulized epinephrine delivered by IPPB. Anesthesiology 31: 581 (1969).

32. SELlick, B.A. Cricoid pressure to control regurgitation of stomach contents during induction of anaesthesia: preliminary communication. Lancet 2: 404 (1961).

33. WrLson, R.D. Current status of ketamine. Regional Refresher Courses in Anesthesiology ASA 1: 157 (1973). 